05

\title{
Затухание упругого предвестника и откол в беспористой керамике карбида вольфрама
}

\author{
(C) A.C. Савиных, ${ }^{1,2}$ И.А. Черепанов, ${ }^{3}$ C.B. Разоренов, ${ }^{1,2}$ K. Mandel, ${ }^{4}$ L. Krüger ${ }^{4}$ \\ ${ }^{1}$ Институт проблем химической фризики РАН, \\ 142432 Черноголовка, Россия \\ ${ }^{2}$ Национальный исследовательский Томский государственный университет, \\ 634050 Томск, Россия \\ ${ }^{3}$ Московский государственный университет им. М.В. Ломоносова, \\ 119991 Москва, Россия \\ ${ }^{4}$ Технический университет „Фрайбергская горная академия“, \\ 09599 Фрайберг, Германия \\ e-mail: savas@ficp.ac.ru
}

(Поступило в Редакцию 4 июля 2018 г.)

С целью определения возможного вклада релаксационных процессов в сопротивление высокоскоростному деформированию проведены измерения эволюции волн ударного сжатия в керамике карбида вольфрамa (WC), изготовленной методом плазменного искрового спекания при максимальном напряжении сжатия $27 \mathrm{GPa}$. Выявлено сильное затухание упругого предвестника при изменении толщины образцов от 0.15 до $4 \mathrm{~mm}$. При максимальных напряжениях ударного сжатия, в 2 раза превышающих динамический предел упругости, регистрируется уменьшение величины откольной прочности на $\sim 30 \%$ от ее значения в упругой области.

DOI: $10.21883 /$ JTF.2019.03.47174.263-18

\section{Введение}

Высокотвердые керамики наряду с широким применением в различных отраслях промышленности часто используются в условиях, сопряженных с интенсивными ударными воздействиями. В силу дороговизны сложных керамических изделий актуальным становится прогнозирование результатов ударных воздействий методами компьютерного моделирования. Для построения адекватных моделей и определяющих соотношений, описывающих сопротивление высокоскоростному деформированию и разрушению в условиях высокоскоростного удара, важно, в частности, правильно оценить вклад релаксации напряжений в этом временном диапазоне.

В обзоре [1] суммированы данные о затухании динамического предела упругости высокотвердых хрупких материалов. Согласно этой работе, в плосковолновых экспериментах с керамикой карбида бора регистрируется затухание упругого предвестника с релаксацией напряжений за его фронтом, в доломите обнаружено незначительное затухание, плотный известняк демонстрирует незначительное или отсутствие затухания. Незначительное затухание упругого предвестника обнаружено и в экспериментах с кварцитом [2] и керамикой оксида алюминия [3]. В работе [4] показано отсутствие зависимости динамического предела упругости керамики оксида алюминия от толщины образца.

Эксперименты с горячепрессованным бериллием S$200 \mathrm{~F}$ [5] показали монотонное затухание его динамического предела упругости с 0.14 до $0.08 \mathrm{GPa}$ на образцах толщиной от 4 до $8 \mathrm{~mm}$. В недавней работе [6] зарегистрировано затухание упругого предвестника в керамике оксида алюминия и найдено, что уменьшение толщины от 3 до $0.25 \mathrm{~mm}$ привело к возрастанию величины динамического предела упругости с 6.5 до $13 \mathrm{GPa}$ при комнатной температуре образцов. Формирование зуба текучести в керамике оксида алюминия начинается при начальных температурах, превышающих $800 \mathrm{~K}$, в образцах толщиной менее $3 \mathrm{~mm}$.

В работе [7] проведены эксперименты по ударноволновому нагружению керамики оксида алюминия, полученной методом плазменного искрового спекания. Показано, что динамический предел упругости исследованной керамики, измеренный для образцов толщиной от 0.28 до $6 \mathrm{~mm}$, уменьшается с 21 до $12 \mathrm{GPa}$ соответственно. Откольная прочность образцов толщиной $3 \mathrm{~mm}$ монотонно падает с $\sim 1.5$ до $\sim 0.3 \mathrm{GPa}$ при увеличении максимального напряжения сжатия до $29 \mathrm{GPa}$, превышающего динамический предел упругости более чем в 2 раза. Эксперименты с реакционно спеченной керамикой карбида кремния толщиной от 0.5 до $8.3 \mathrm{~mm}$, результаты которых представлены в работе [8], не обнаруживают затухания упругого предвестника и показывают, что эволюция волны сжатия соответствует простой волне. Нужно отметить, что образцы, исследованные в этой работе, вырезались электроэрозионным методом практически без какого-либо влияния на их внутреннюю структуру.

В настоящей работе исследована эволюция волны сжатия по мере ее распространения в беспористой керамике карбида вольфрама. Подобные измерения для металлов и сплавов обычно демонстрируют затухание упругих 
Таблица 1. Механические свойства исследованной керамики WC

\begin{tabular}{c|c|c|c|c|c|c|c|c|c}
\hline $\begin{array}{c}\rho_{0}, \\
\mathrm{~g} / \mathrm{cm}^{3}\end{array}$ & $\begin{array}{c}\rho_{\text {rel }}, \\
\%\end{array}$ & $\begin{array}{c}c_{s}, \\
\mathrm{~m} / \mathrm{s}\end{array}$ & $\begin{array}{c}c_{l}, \\
\mathrm{~m} / \mathrm{s}\end{array}$ & $v$ & $\begin{array}{c}E, \\
\mathrm{GPa}\end{array}$ & $\begin{array}{c}G, \\
\mathrm{GPa}\end{array}$ & $\begin{array}{c}d_{\mathrm{WC}} \\
\mathrm{nm}\end{array}$ & $\mathrm{HV} \mathrm{10}$ & $\begin{array}{c}K_{\mathrm{I}} \\
\mathrm{MPa} \cdot \mathrm{m}^{1 / 2}\end{array}$ \\
\hline 15.66 & 99.9 & 4384 & 7164 & 0.201 & 723 & 301 & 330 & 2690 & 6.7
\end{tabular}

Примечание: здесь $\rho_{0}$ - измеренная плотность образцов, $\rho_{\text {rel }}$ отношение измеренной плотности к теоретической, $c_{s}-$ сдвиговая скорость звука, $c_{l}$ - продольная скорость звука, $v-$ коэффициент Пуассона, $E, G$ - модуль Юнга и модуль сдвига, $d_{\mathrm{WC}}-$ средний размер зерна. HV 10 - твердость по Виккерсу, $K_{\mathrm{I} c}-$ критический коэффициент интенсивности напряжений.

предвестников ударных волн, анализ которого дает сведения о начальной скорости релаксации напряжений и соответствующей скорости пластической деформации.

\section{Материал и постановка экспериментов}

Беспористые образцы керамики карбида вольфрама были изготовлены путем спекания чистого порошка карбида вольфрама марки DN-4 (H.C. Starck, Germany) плазменно-искровым методом (в англоязычный литературе обозначаемый как SPS — Spark Plasma Sintering [9]) при температуре $1800^{\circ} \mathrm{C}$ в течение $3 \mathrm{~min}$. По сравнению с традиционными методами метод SPS позволяет получать высококачественные спеченные материалы при меньших температурах и за меньшее время. В табл. 1 представлены механические свойства исследованной керамики. Методы определения механических свойств исследованной керамики карбида вольфрама подробно описаны в [10].

Исходные образцы карбида вольфрама представляли собой плоскопараллельные пластины толщиной $4 \mathrm{~mm}$ и диаметром $20 \mathrm{~mm}$. Образцы для ударно-волновых экспериментов с номинальной толщиной $2,1,0.5,0.3$ и $0.15 \mathrm{~mm}$ вырезались из одной исходной пластины электроэрозионным методом и затем шлифовались. Экспериментальные данные для образцов толщиной $4 \mathrm{~mm}$ взяты из работы [10]. Образцы толщиной $4 \mathrm{~mm}$, исследованные в работе [10], и образцы, из которых вырезались пластины меньшей толщины, были изготовлены одновременно и при одних и тех же условиях. Механические свойства изготовленных образцов толщиной $4 \mathrm{~mm}$ не изменялись от образца к образцу в пределах погрешности измерений. Поперечные размеры исследованных образцов были достаточными для обеспечения условия одномерной деформации в течение всего времени регистрации.

Нагружение образцов в экспериментах по определению динамического предела упругости проводилось ударом алюминиевой пластины толщиной $2 \mathrm{~mm}$ со скоростью $1.8 \pm 0.05 \mathrm{~km} / \mathrm{s}$ через алюминиевый экран толщиной $2 \mathrm{~mm}$, что соответствует максимальному напряжению ударного сжатия $\sim 27 \mathrm{GPa}$. Экран использовался для отсечения воздушной волны, образующейся перед летящим ударником. Метание ударников осуществлялось с применением взрывных устройств [11]. Для определения величины критических растягивающих напряжений, образцы нагружались ударом алюминиевой пластины толщиной $0.38 \mathrm{~mm}$ со скоростями $0.62 \pm 0.03,1.2 \pm 0.03 \mathrm{~km} / \mathrm{s}$ и толщиной $2 \mathrm{~mm}$ со скоростью $1.8 \pm 0.05 \mathrm{~km} / \mathrm{s}$. В процессе нагружения образцов с помощью лазерного доплеровского измерителя скорости VISAR [12], имеющего временное разрешение $\sim 1 \mathrm{~ns}$, регистрировались профили скорости свободной поверхности $u_{f s}(t)$.

\section{Обсуждение результатов}

На рис. 1 показаны измеренные профили скорости свободной поверхности образцов карбида вольфрама номинальной толщиной от 0.15 до $4 \mathrm{~mm}$ при ударе алюминиевой пластиной толщиной $2 \mathrm{~mm}$ со скоростью $1.8 \mathrm{~km} / \mathrm{s}$. На волновых профилях регистрируется выход на поверхность упругой ударной волны сжатия, который сопровождается формированием так называемого „зуба“ - ниспадающего профиля, связанного с интенсивным размножением дефектов дислокационного типа и выделением пластического фронта. Затем на поверхность выходит пластическая волна сжатия. На рисунке видно, что регистрируемое максимальное значение скорости свободной поверхности во фронте упругой волны $u_{\mathrm{HEL}}$ увеличивается с уменьшением толщины образца. Релаксация напряжений за фронтом упругого предвестника регистрируется не во всех экспериментах, наиболее отчетливо эффект релаксации наблюдается на образцах толщиной $0.5 \mathrm{~mm}$ и менее. Регистрируемые профили имеют хорошую воспроизводимость от опыта

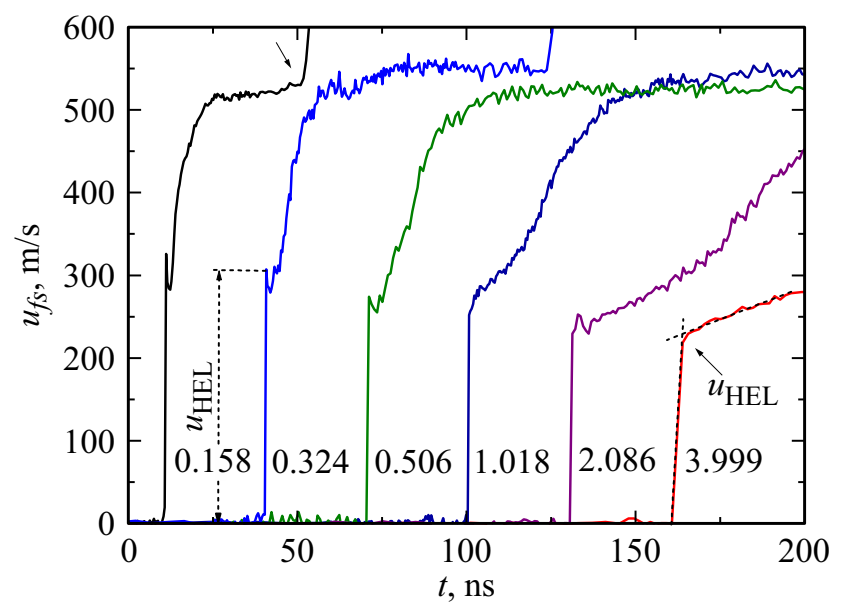

Рис. 1. Профили скорости свободной поверхности образцов керамики карбида вольфрама толщиной от 0.15 до $4 \mathrm{~mm}$ при ударе алюминиевой пластиной толщиной $2 \mathrm{~mm}$ со скоростью $1.8 \mathrm{~km} / \mathrm{s}$. Цифрами указаны толщины образцов в миллиметрах, стрелкой на профиле скорости образца толщиной $0.158 \mathrm{~mm}$ показан выход на свободную поверхность переотраженной волны сжатия. 
Таблица 2. Результаты экспериментов с образцами карбида вольфрама по измерению динамического предела упругости

\begin{tabular}{lcc}
\hline$h, \mathrm{~mm}$ & $u_{\mathrm{HEL}}, \mathrm{m} / \mathrm{s}$ & $\sigma_{\mathrm{HEL}}, \mathrm{GPa}$ \\
\hline 0.158 & 325 & 18.18 \\
0.164 & 314 & 17.57 \\
0.315 & 311 & 17.41 \\
0.324 & 304 & 17.01 \\
0.506 & 274 & 15.34 \\
0.505 & 275 & 15.39 \\
1.018 & 264 & 14.77 \\
2.086 & 240 & 13.46 \\
$3.995[10]$ & 232 & 13.01 \\
$3.999[10]$ & 227 & 12.68
\end{tabular}

к опыту и отличаются отсутствием осцилляций, что свидетельствует о гомогенности деформирования в области пластического течения.

На волновых профилях для образцов толщиной меньше $2 \mathrm{~mm}$ регистрируется второй подъем скорости, вызванный переотражением волны разрежения от поверхности экран-образец. Так как динамический импеданс керамики WC выше, чем динамический импеданс алюминиевого экрана, отражение волны разрежения происходит с изменением ее знака, в результате чего переотраженная волна является волной сжатия. В лагранжевых координатах средние значения скорости фронтов волны разрежения, распространяющейся по сжатому материалу, и волны сжатия в разгруженном материале находятся в диапазоне $7.56 \pm 0.1 \mathrm{~km} / \mathrm{s}$, что несколько превышает продольную скорость звука при нулевом давлении. Данный факт косвенно свидетельствует о том, что материал не претерпевал разрушения в процессе одномерного сжатия и последующей разгрузки, поскольку наличие трещин и других деформационных дефектов оказывает значительное влияние на скорость распространения возмущений.

Значение динамического предела упругости $\sigma_{\mathrm{HEL}}$ вычислялось по измеренному профилю скорости свободной поверхности как $\sigma_{\mathrm{HEL}}=\rho_{0} c_{l} u_{\mathrm{HEL}} / 2$ [11], где $u_{\mathrm{HEL}}-$ максимальное значение скорости свободной поверхности во фронте упругой волны сжатия (рис. 1). Полученные результаты представлены в табл. 2. На рис. 2 приведены результаты обработки волновых профилей, показанных на рис. 1, в виде зависимости динамического предела упругости от толщины образца в логарифмических координатах. Из рисунка видно, что значение динамического предела упругости керамики карбида вольфрама уменьшается экспоненциально с ростом пройденного упругой волной расстояния. При этом во всех случаях наблюдается небольшой разброс данных при одинаковых условиях экспериментов. Полученные данные по затуханию предвестников на рис. 2 могут быть с приемлемой точностью описаны степенным со- отношением $\sigma_{\mathrm{HEL}}=S\left(h / h_{0}\right)^{-\alpha}$, где $h_{0}=1 \mathrm{~mm}$, а параметры $S$ и $\alpha$ составляют $S=14.72 \mathrm{GPa}, \alpha=0.107$.

На рис. 2 полученные значения динамического предела упругости керамики WC также сопоставлены с литературными данными. В работе [13] исследовалось поведение керамики горячепрессованого карбида вольфрама при ударном сжатии. Измеренный динамический предел упругости для образцов толщиной от 3 до $6 \mathrm{~mm}$ оказался равен $6.6 \pm 0.5 \mathrm{GPa}$. Образцы толщиной $4 \mathrm{~mm}$, полученные методом SPS, демонстрируют двукратное увеличение напряжения упругого сжатия по сравнению с горячепрессованными, что можно объяснить их меньшей пористостью. Введение добавок к керамике карбида вольфрама уменьшает ее $\sigma_{\mathrm{HEL}}$ более чем в 2 раза для

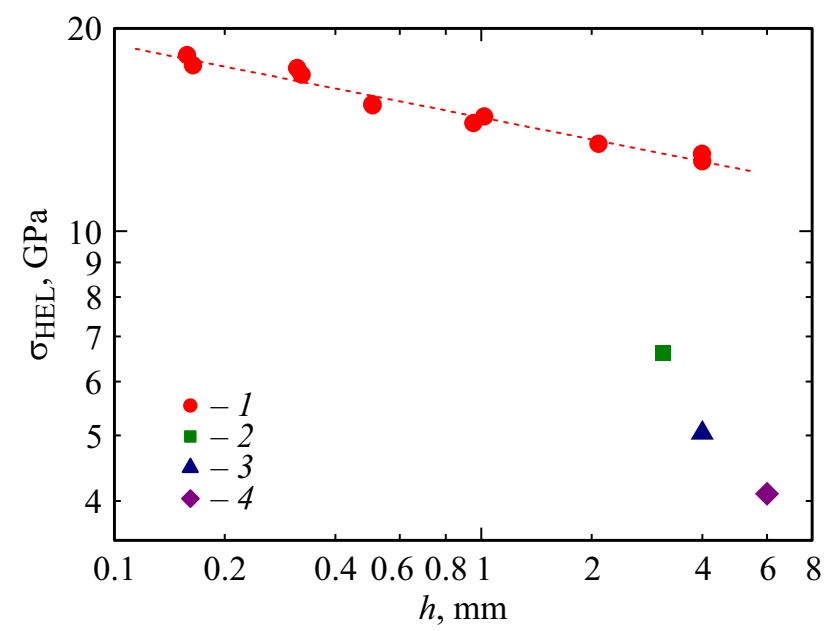

Рис. 2. Зависимость динамического предела упругости керамики WC от толщины образца: 1 - данные, полученные в настоящей работе; 2 - горячепрессованный $\mathrm{WC}$, Cercom [13]; $3-\mathrm{WC}+\mathrm{Co}(6 \%), \quad$ SPS-метод $[10] ; 4-$ $\mathrm{WC}+\mathrm{Co}(5.7 \%)+\mathrm{Ta}(1.9 \%)[14]$.

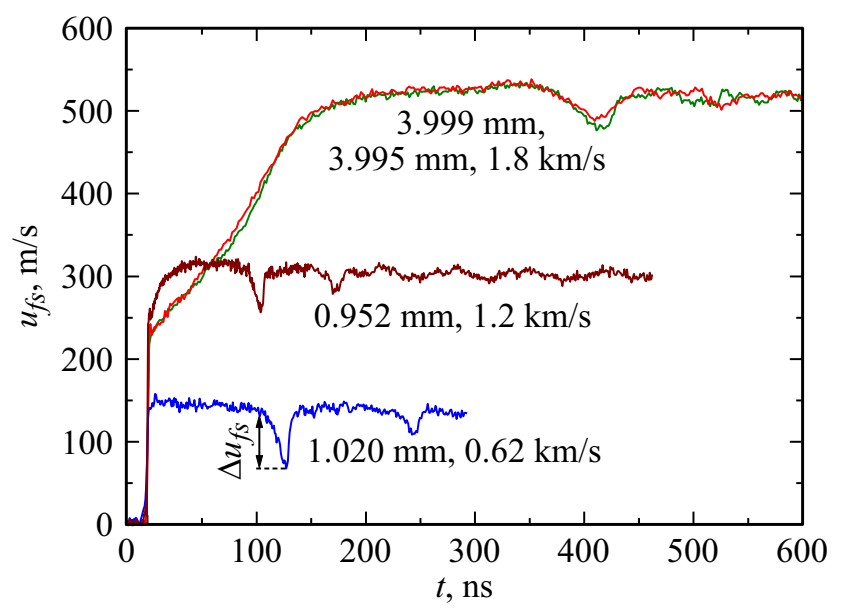

Рис. 3. Профили скорости свободной поверхности образцов керамики карбида вольфрама при ударе алюминиевой пластиной со скоростью 1.8 [10], 1.2 и $0.62 \mathrm{~km} / \mathrm{s}$. Цифрами указаны толщины образцов и скорость соударения алюминиевого ударника с образцом. 
Таблица 3. Результаты экспериментов с образцами карбида вольфрама по измерению откольной прочности

\begin{tabular}{lccc}
\hline$h, \mathrm{~mm}$ & $\Delta u_{f s}, \mathrm{~m} / \mathrm{s}$ & $\sigma_{\max }, \mathrm{GPa}$ & $\sigma_{s p}, \mathrm{GPa}$ \\
\hline 1.020 & 73 & 8.15 & 4.09 \\
0.952 & 56 & 17.33 & 3.13 \\
$3.995[10]$ & 44.3 & 27.5 & 2.48 \\
$3.999[10]$ & 52.5 & 27.3 & 2.93
\end{tabular}

Примечание: $\sigma_{\max }$ - максимальное напряжение при ударном сжатии.

керамики, полученной методом SPS [10], и почти в 3 раза для горячепрессованной керамики [14].

На рис. 3 показаны профили скорости свободной поверхности образцов карбида вольфрама номинальной толщиной $4 \mathrm{~mm}[10]$ при ударе алюминиевой пластиной толщиной $2 \mathrm{~mm}$ со скоростью $1.8 \mathrm{~km} / \mathrm{s}$ и номинальной толщиной $1 \mathrm{~mm}$ при ударе алюминиевой пластиной толщиной $0.38 \mathrm{~mm}$ со скоростью 1.2 и $0.62 \mathrm{~km} / \mathrm{s}$. Coотношение толщин образца и ударника в этих экспериментах подобрано таким образом, чтобы получить условия откольного разрушения образца, и тем самым определить его откольную прочность. Волновые профили, представленные на рис. 3, демонстрируют все особенности разрушения упруго-пластического материала в условиях откола: выход на поверхность образца упругопластической волны сжатия, следующую за ней волну разрежения, момент откольного разрушения материала, совпадающий по времени с первым минимумом скорости на профиле волны, формирование импульса сжатия, так нназываемого „откольного импульса“, и последующие колебания скорости поверхности, связанные с его реверберацией в откольной пластине. В эксперименте при нагружении ударником, разогнанным до скорости $0.62 \mathrm{~km} / \mathrm{s}$, реализуемое максимальное давление сжатия ниже динамического предела упругости, т.е. откольное разрушение образца происходит в упругой области.

Откольная прочность рассчитывалась по измеренной величине спада скорости в волне разрежения перед фронтом откольного импульса $\Delta u_{f s}$ (рис. 3 ) по формуле [11]: $\sigma_{s p}=\rho_{0} c_{l} \Delta u_{f s} / 2$. Полученные значения откольной прочности при оцененной скорости деформирования в волне разрежения, равной $\sim 3 \cdot 10^{5} \mathrm{~s}^{-1}$, представлены в табл. 3.

На рис. 4 представлена зависимость откольной прочности от максимального напряжения керамики карбида вольфрама в сопоставлении с данными из литературы. Для расчета отношения максимального напряжения к динамическому пределу упругости использовалась измеренная соответствующая толщине образца величина $\sigma_{\text {HEL. }}$ Отчетливо видно, что наибольшее значение величины откольной прочности реализуется в упругой области. При небольшом превышении динамического предела упругости ее величина уменьшается сразу на $\sim 25 \%$ и убывает с дальнейшим ростом давления.

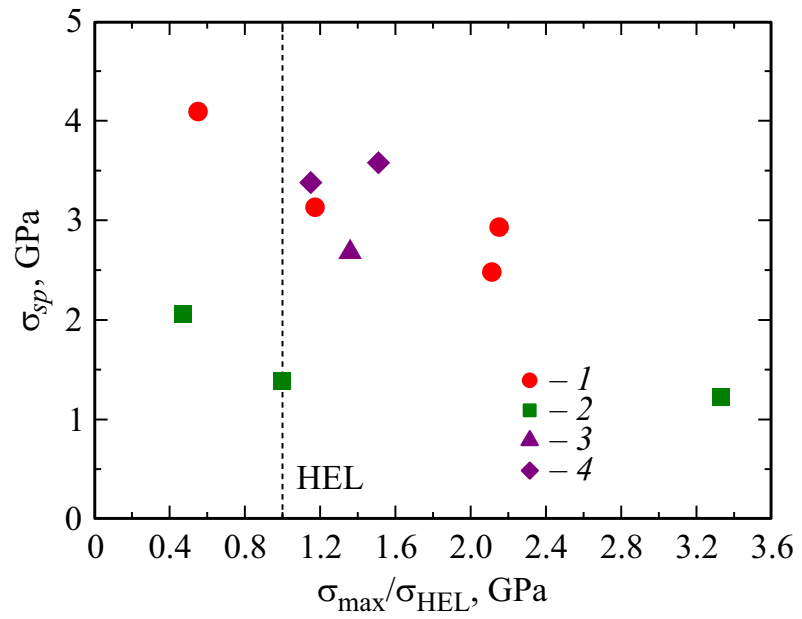

Рис. 4. Зависимость откольной прочности керамики карбида вольфрама от максимального напряжения сжатия: 1 данные, полученные в настоящей работе и работе [10] (при максимальной давлении); 2 - горячепрессованный WC, $\sigma_{\mathrm{HEL}}=7.2 \mathrm{GPa}[15] ; 3-\mathrm{WC}+5.7 \% \mathrm{Co}+1.9 \% \mathrm{Ta}[14] ; 4-$ $\mathrm{WC}+3-4 \% \mathrm{Ni}+0.4-0.8 \% \mathrm{Fe}[14]$.

Откольная прочность горячепрессованного карбида вольфрама исследовалась в работе [15]. Было показано, что рост напряжения сжатия в ударной волне с 3.4 до $7.2 \mathrm{GPa}$ приводит к резкому уменьшению значения откольной прочности с 2.06 до $1.38 \mathrm{GPa}$, дальнейший рост максимального напряжения сжатия до $24 \mathrm{GPa}$ снижает это значение незначительно до $1.22 \mathrm{GPa}$. Сопоставление полученных в настоящей работе результатов с данными [15] демонстрирует двукратное увеличение откольной прочности образцов керамики карбида вольфрама, изготовленных методом искрового плазменного спекания, в близком диапазоне напряжений сжатия. Полученные значения откольной прочности карбида вольфрама, имеющего $\sigma_{\mathrm{HEL}}=4.1 \mathrm{GPa}$, в работе $[14] \mathrm{c}$ добавками $5.7 \% \mathrm{Co}+1.9 \%$ Та и $3-4 \% \mathrm{Ni}+0.4-0.8 \% \mathrm{Fe}$ находятся на одном уровне значений с беспористым карбидом вольфрама (рис. 4) при напряжениях сжатия превышающих $\sigma_{\mathrm{HEL}}$, что подтверждает упрочняющее влияние добавок.

\section{Заключение}

Анализ измеренных профилей скорости свободной поверхности образцов керамики WC толщиной от 0.15 до $4 \mathrm{~mm}$, изготовленных методом искрового плазменного спекания, показывает сильное затухание упругого предвестника по мере его распространения. В экспериментах с образцами толщиной $0.5 \mathrm{~mm}$ и менее отчетливо регистрируется релаксация напряжений за фронтом упругого предвестника. Измеренные значения динамического предела упругости и откольной прочности исследованной керамики более чем в 2 раза превышают таковые для горячепрессованных керамик $[13,15]$. При максималь- 
ных напряжениях ударного сжатия, примерно в 2 раза превышающих динамический предел упругости этой керамики, наблюдается уменьшение величины откольной прочности на треть от ее значения в упругой области. Результаты экспериментов не обнаруживают признаков разрушения материала при ударном сжатии.

Работа выполнена по теме государственного задания, № гос. регистрации 0089-2014-0016, и в рамках Программы фундаментальных исследований Президиума РАН № 13 „Конденсированное вещество и плазма при высоких плотностях энергии“ по теме научного направления „Быстрые физико-химические превращения и разрушение твердых тел и жидкостей“.

\section{Список литературы}

[1] Grady D.E. // Mechan. Material. 1998. Vol. 29. N 3-4. P. 181-203. DOI: 10.1016/S0167-6636(98)00015-5

[2] Ahrens T.J., Duvall G.E. // J. Geophys. Res. 1966. Vol. 71. P. 4349-4360.

[3] Rosenberg Z., Brar N.S., Bless S.J. // J. Phys. Colloq. 1988. Vol. 49. N C3. P. 707-711. DOI: 10.1051/jphyscol:19883100

[4] Cagnoux J., Longy F. In: Shock Waves in Condensed Matter - 1987. Amsterdam: Elsevier, 1988. P. 293-296.

[5] Adams C.D., Anderson W.W., Blumenthal W.R., Gray G.T. III // J. Phys. Conf. Ser. 2014. Vol. 500. P. 112001. DOI: 10.1088/1742-6596/500/11/112001

[6] Zaretsky E.B. // J. Appl. Phys. 2013. Vol. 114. P. 183518. DOI: $10.1063 / 1.4830014$

[7] Girlitsky I., Zaretsky E., Kalabukhov S., Dariel M.P., Frage N. // J. Appl. Phys. 2014. Vol. 115. P. 243505. DOI: $10.1063 / 1.4885436$

[8] Савиных А.С., Канель Г.И., Разоренов С.В., Румянцев В.И. // ЖТФ. 2013. Т. 83. Вып. 7. С. 43-47. [Savinykh A.S., Kanel G.I., Razorenov S.V., Rumyantsev V.I. // Tech. Phys. 2013. Vol. 58. N 7. P. 973-977.] DOI: $10.1134 / \mathrm{S} 1063784213070207$

[9] Guillon O., Gonzalez-Julian J., Dargatz B., Kessel T., Schierning G., Rathel J., Herrmann M. // Advan. Engineer. Mater. 2014. Vol. 16. N 7. P. 830-849.

DOI: $10.1002 /$ adem.201300409

[10] Савиных A.C., Mandel K., Разоренов С.B., Krüger L. // ЖТФ. 2018. Т. 18. Вып. 3. С. 368-373. [Savinykh A.S., Mandel K., Razorenov S.V., Krueger L. // Tech. Phys. 2018. Vol. 63. N 3. P. $357-362$.] DOI: $10.1134 / \mathrm{S} 1063784218030210$

[11] Канель Г.И., Разоренов С.В., Уткин А.В., Фортов В.Е. Ударно-волновые явления в конденсированных средах. М.: Изд-во Янус-К, 1996. 407 с.

[12] Barker L.M., Hollenbach R.E. // J. Appl. Phys. 1972. Vol. 43. N 11. P. 4669-4675. https://doi.org/10.1063/1.1660986

[13] Dandekar D.P., Grady D.E. In: Shock Compression of Condensed Matter - 2001 / Ed. by M.D. Furnish, N.N. Thadhani, Y. Horie. AIP CP 620. 2002. P. 783-786.

[14] Grady D.E. Dynamic Properties of Ceramic Materials. SAND94-3266. February 1995. 99 p.

[15] Dandekar D.P. Spall Strength of Tungsten Carbide. ARL-TR-3335. September 2004. 22 p. 